\title{
THE POTENTIAL OF AUGMENTED REALITY TO CHANGE THE BUSINESS
}

\author{
G. Kiryakova*, N. Angelova, L.Yordanova
}

Faculty of Economics, Trakia University - Stara Zagora, Bulgaria

\begin{abstract}
Augmented Reality is among the fastest growing technologies and has been implemented in different fields of life. It allows users to see and percept the physical world around them in a new more engaging and interactive way using their mobile devices. The business is a field where innovative technologies are rapidly trying to complement or replace traditional approaches. The dilemma is: Is it possible Augmented Reality to be used as an effective tool for business? The aim of the current work is to reveal the potential of Augmented Reality technology to improve companies' activities and campaigns and make them more interactive and creative.
\end{abstract}

Key words: Augmented Reality, business, technology, retail, manufacturing, marketing, advertising, tourism

\section{INTRODUCTION}

In the modern world, the success in business is invariably linked to taking rapid and decisive steps for the deployment of innovative technologies. Companies that delay these actions lag behind competitors. The crucial factors in the perception of each technology are the identification of new trends and their accompanying tools, as well as the intention to exploit all benefits of the technology in the most effective way (1). Technological innovations in the information society have a transformative impact and lead to substantial changes in the way companies carry out their activities.

According to Gartner, Augmented and Virtual reality are among the ten leading strategic technological trends for 2017 (2). The boundaries between the digital and the physical world are becoming increasingly blurred with these technologies. The digital world is not only a reflection of the physical environment, where people live and work, but it complements the real world with new, more personalized and sensuous feelings. Businesses show an

\footnotetext{
*Correspondence to: Gabriela Kiryakova, Faculty of Economics, Trakia University - Stara Zagora, Bulgaria, gabriela@uni-sz.bg
}

The dilemma is: Is it possible Augmented Reality to be used as an effective tool for business? The innovative technology links reality and the digital world more closely and indissolubly and creates prerequisites for new business models (2). The aim of the current work is to reveal the potential of Augmented Reality technology to improve companies' activities and campaigns and make them more interactive and creative.

\section{AUGMENTED REALITY TECHNOLOGY}

Augmented Reality has a relatively long history, but prolonged time was in the shadow of Virtual Reality. Augmented Reality comes out in the spotlight and becomes the subject to increased interest with its application in the popular game Pokémon Go. The game helps rediscover the capabilities of the technology that allows mixing the real and digital worlds.

\section{Nature of Augmented Reality}

Augmented Reality is a system, which has the following characteristics (3):

- Combines real and virtual objects. Virtual and real objects coexist together at the same time, in the same place.

- Interactivity in real time. Users can 
interact with virtual content, which responds to their actions.

- Virtual objects are registered in the physical 3D world. There is a geometric alignment of virtual objects to real ones in the real world.

Augmented Reality expands the real world by adding layers of virtual content to the reality. In this sense, Augmented Reality supplements the reality rather than completely replacing it.

Augmented Reality removes the barriers between the physical and the virtual world by playing the role of a bridge between them and creates prerequisites for integrating all human senses into perception and interaction with the digital world (2). The technology integrates and mixes two worlds, supplementing and enriching each other, to achieve the goal of improving the sense of the real world.

\section{Augmented Reality vs. Virtual Reality}

Whenever it comes to Augmented Reality, analogies to Virtual Reality are made.

Virtual Reality replaces the real world with a completely digitally recreated world. Users are completely immersed in the synthetic environment and they cannot see, feel or interact with the physical world around them. Virtual Reality is a powerful tool for perception of the digital content since it is the only environment where users are fully focused on it.

Unlike Virtual Reality, Augmented Reality creates virtual objects that are superimposed upon the real world. The technology provides virtual details for realworld objects, which expand and enrich the world around the users. Augmented Reality allows users to stay in touch with the real world, interact with both virtual content as well as the world, which surrounds them, at the same time. The basic idea of technology is to immerse users in the real world by providing information about objects or scenes they are seeing in the real time (1).

\section{Types of Augmented Reality}

Several classifications of Augmented Reality can be made according to different criteria.
KIRYAKOVA G., et. al. Depending on the hardware devices, which users use, there are:

- Stationary Augmented Reality Systems. They are motionless systems that are usually equipped with more powerful cameras and can provide accurate recognition of objects and scenes from the reality. This type of Augmented Reality systems are suitable and are used in virtual try-and-buy projects in physical stores.

- Spatial Augmented Reality Systems. They project the virtual content directly on the real-world objects in actual dimensions and proportions. These systems are subject to increased interest from the automotive industry.

- Desktop Augmented Reality. Augmented Reality applications use the computer's camera to recognize the realworld objects and embed virtual objects to them. Virtual try-and-buy projects in online stores are usually based on Desktop Augmented Reality.

- Handheld Devices. Handheld Devices are also known as mobile Augmented Reality, which is extremely popular due to the fact that mobile devices (such as phones, tablets, etc.) are widely spread nowadays. Most of the mobile Augmented Reality applications use the device's GPS built-in transmitter to determine the position of the users. Depending on the position, applications provide information in various forms (text, images, audio, and video) that is directly related to users' location and is integrated to their real environment.

- Head-mounted Displays. These devices provide a combined image of the physical world and virtual objects in front of the user's field of view. Depending on the underlying technology, devices can be divided into Optical and Video Headmounted Displays. The most popular representative of this group of hardware devices are smart glasses. Popular examples are Google Glass, Vuzix Smart Glasses, Sony Smart EyeGlass, CastAR.

- Contact lenses. They are the future of Augmented Reality. Contact lenses are in the process of development and will allow users to get a combined image of reality with embedded virtual content. 
Depending on how objects or scenes are identified, the Augmented Reality is divided into:

\section{- Vision-based Augmented Reality.} Vision-based Augmented Reality can be marker-based or markerless. Markerbased Augmented Reality applications use the device's camera to recognize and interpret markers (usually black and white barcode images). The software analyzes the marker and creates virtual objects that are displayed on the device's screen, integrated to the recognized real-world objects. The markerless Augmented Reality is based on the recognition of realworld objects (photographs, magazine covers, objects, faces, scenes, etc.). The software recognizes the objects according to their specific features that distinguish them from the surrounding objects.

- Location-based Augmented Reality. Location-based Augmented Reality is a markerless Augmented Reality, where applications use the device's GPS capabilities to determine the position of the device (respectively of its owner), and provide information related to this location - for example, information about hotels, restaurants, museums and others that are close to the user.

\section{AUGMENTED REALITY AS AN EFFECTIVE TOOL FOR BUSINESS}

The expectations for a widespread introduction of Augmented Reality in almost all spheres of life are based on the fact that the hardware, which supports the technology, is already available. Most users have a variety of mobile devices smart phones, tablets, smart wearable devices, and so on. According to International Data Corporation, the total revenue for Virtual and Augmented Reality is expected to increase from $\$ 5.2$ billion in 2016 to over $\$ 162$ billion in 2020. More than half of revenue comes from the sales of Virtual and Augmented Reality hardware. Software is a smaller revenue source, which grew by more than $200 \%$ in 2016 compared to the previous year (4). To use Augmented Reality, it is necessary to install a suitable, specially developed Augmented Reality application or a standard Augmented Reality Browser that enables users to become part of the mixed reality.

On the other hand, there is a tendency more and more users to use their mobile devices not only for entertainment, but also for training, work and business.

Augmented Reality is a technology that is embraced and becomes part of the strategies of an increasing number of companies that operate in various business areas - manufacturing, trade, advertising, tourism and others.

\section{Retail}

E-commerce is integral part of today's business. More and more people shop online that leads to the need to improve the processes of online commerce. The implementation of new technologies can help companies make customers feel more satisfied with the purchases they made.

Augmented Reality can change the nature and essence of trade - both traditional (in the real world) and electronic. The efforts are focused on utilizing the potential of the technology to personalize and improve users' perceptions during the purchases, their experience and satisfaction, enhance the interactivity of the shopping. As a consequence, there will be increased sales (increased revenue for companies), customers' loyalty, users' willingness to recommend their experiences to friends and acquaintances.

In online commerce customers do not have opportunities to interact with the products - they cannot touch, try or smell them, which is often an obstacle to making real orders and purchases. Virtual try-and-buy experience is the first step companies take in using Augmented Reality technology to increase customer engagement and provoke online orders and purchases (5). Augmented Reality applications allow creating virtual fitting rooms where customers can try goods virtually. This approach is popular among companies that offer cosmetics, jewelry, watches, glasses, etc. They can integrate fitting room modules into their e-commerce websites (Figure 1). The possibilities to offer a new, memorable, personalized experience for customers, as a result of combining the 
convenience of technology with the experience of physical trading, drive more visitors to online stores. More visitors,
KIRYAKOVA G., et. al. whose expectations are satisfied, lead to more sales and revenues for online stores.

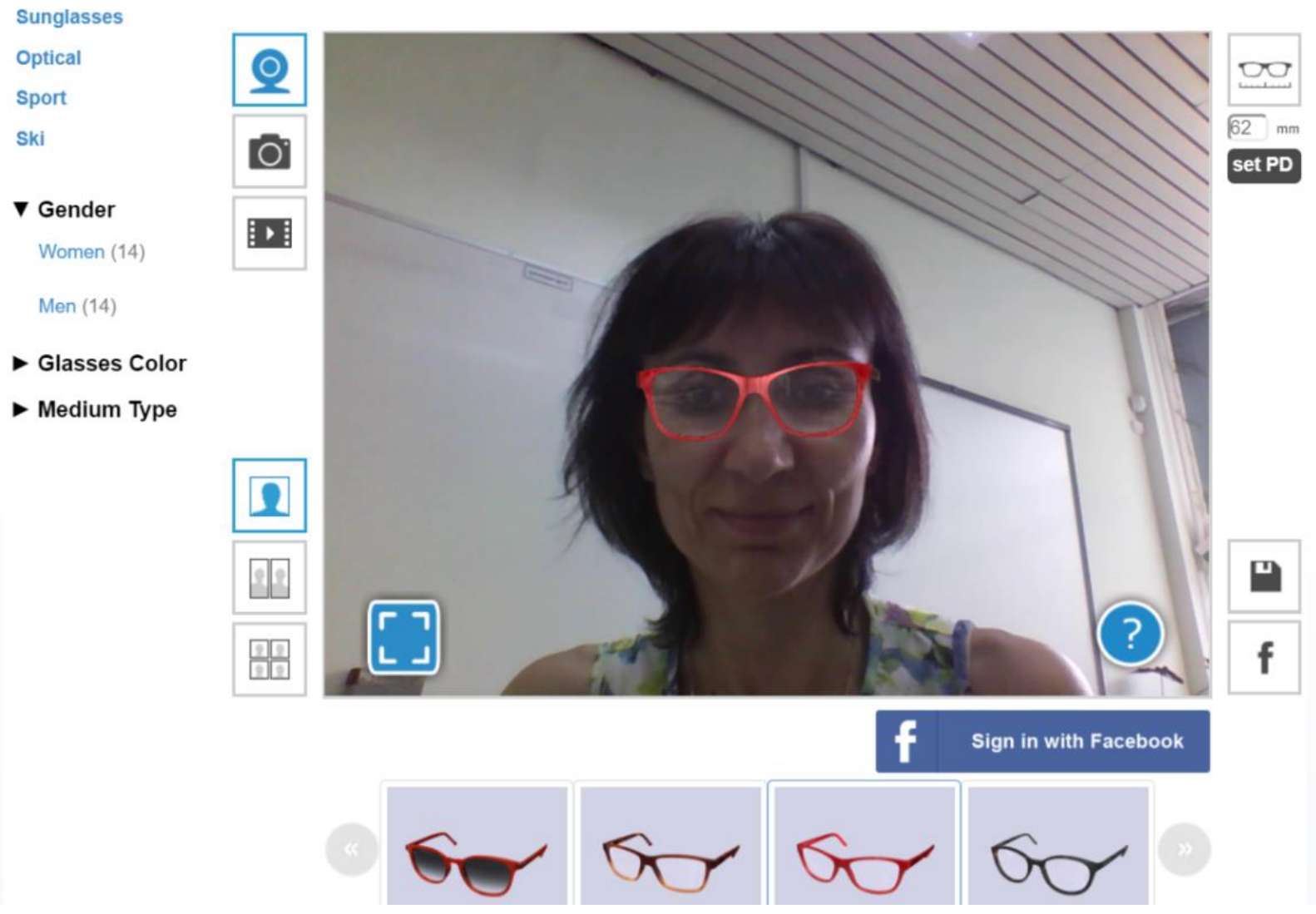

Figure 1. Virtual try-on solution (Acep TryLive Eyewear).

Augmented Reality is a subject of interest not only to e-commerce representatives but also to physical traders. Their aim is to become competitive to online retailers in terms of the unique experience they offer. Virtual fitting rooms can be created using Augmented Reality technology in physical stores and customers are able to interact with digital content and have new unique experiences.

\section{Manufacturing and maintenance}

Augmented Reality can be used in almost any stage of the process of design and manufacturing of the products - from the design phase to the production stages and subsequent maintenance and repair of the products.

Augmented Reality helps engineers and designers design products in the environment where they will be used. The technology allows them to take into account all factors, features or constraints imposed by surrounding environment. Augmented Reality supports the creation of precise projects and their optimization. Designed products can be tested, analyzed, subjected to simulations that allow consideration of various factors in their use over time.

The products, created nowadays, are becoming more and more complex, which complicates their manufacturing. Augmented Reality applications can provide information in various forms, including online resources, to the staff about the manufacturing operations at the right time (6). The digital content, added to the reality, improves the efficiency of work and optimizes production processes.

Augmented Reality can also assist service workers in the diagnosis of breakdowns and repair activities. The mechanics can see animated parts that need to be repaired or replaced, what tools to use and the sequence of actions (Figure 2). They receive additional three-dimensional information or audio instructions for each working step. Augmented Reality makes repair activities easier, shortens the time they take and improves their quality. 


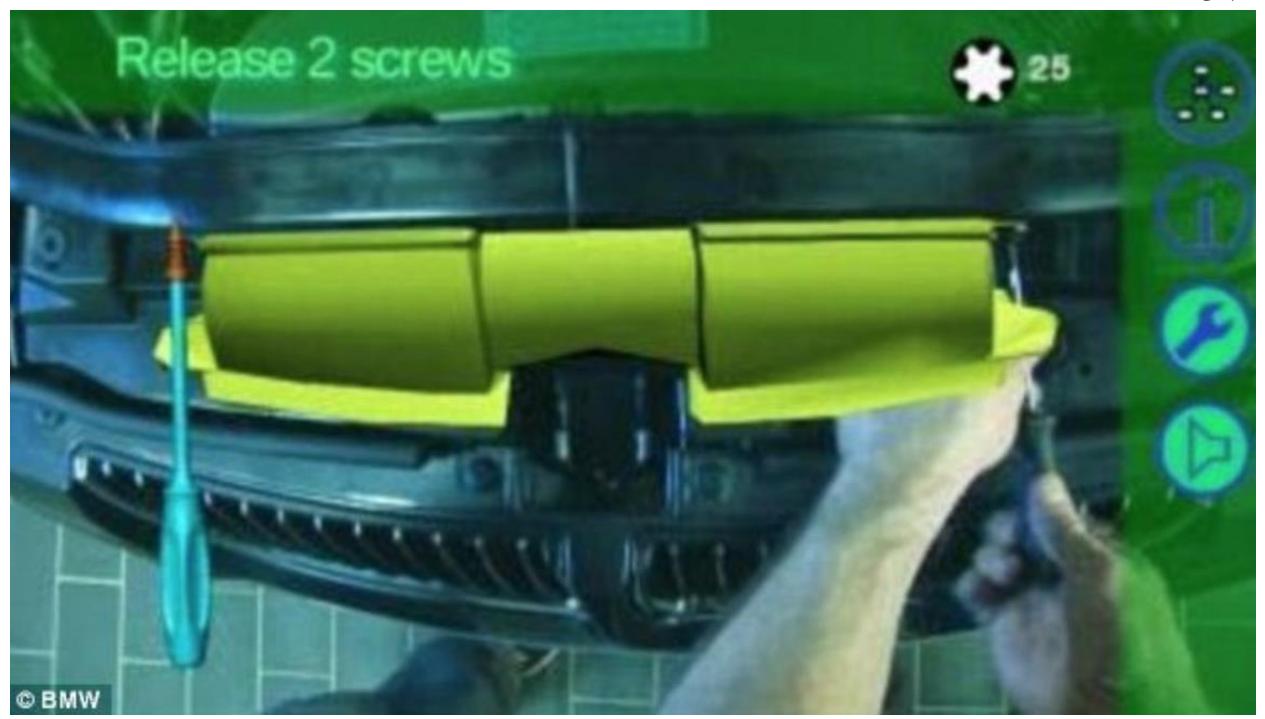

Figure 2. BMW Augmented Reality Glasses (7).

\section{Tourism}

The tourism industry aims to offer and sell experiences and unforgettable memories to consumers (8). Augmented Reality can make a significant contribution to achieving these goals by enriching tourists' experiences and providing new ways of visitors service.

Users can "experience" each destination before they visit it through Augmented Reality. On one side, the technology allows users to determine which destination is the best choice for them. On the other side, the technology can improve and enrich the overall perceptions and experience of tourists during their visits.

Users can use Augmented Reality to have quick and easy access to information that is vital to their enjoyment and safety (9). The tourists receive data in various forms (opinions, reviews, comments) about hotels, restaurants, museums, landmarks and other locations around them in real time. Data enrich the reality around visitors and makes their experiences even more exciting and memorable.

Augmented Reality can be used in museums and galleries to provide multimedia information equivalent to traditional audio and video tours, but much richer in the sense of content and form. Many Augmented Reality applications supply information in the form of educational games, combining learning and entertainment, to make visitors' experience more interactive and interesting.

Another application of Augmented Reality in tourism is the possibility to translate from one language to another in real time. There are a number of applications, such as Google translator, which provide real-time text translation of labels, menus, signs using the camera of the mobile devices (9) - Figure 3.

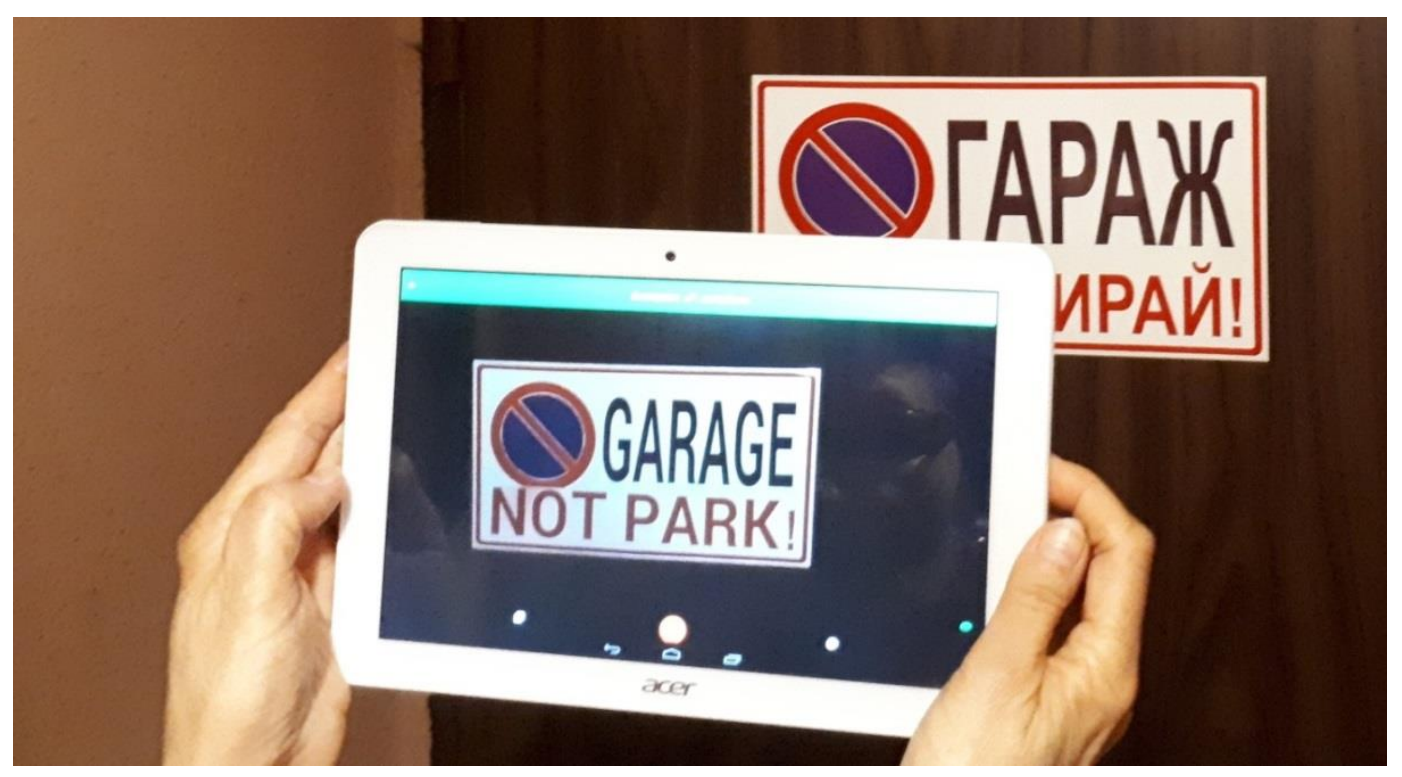

Figure 3. Translation of signs with Google translator. 


\section{Marketing and Advertising}

Augmented Reality contributes to the creation of interactive marketing and advertising campaigns that engage customers' attention and involve them as active participants. Augmented Reality can be considered as the perfect tool for increasing sales.
KIRYAKOVA G., et. al. Augmented Reality applications allow digital content come to life. Print materials can be turned to interactive with additional 3D images or they can come to life with animations or videos (Figure 4). The technology gives users a 360 degree view of the products. It allows customers to change components or details of the products according to their personal preferences.
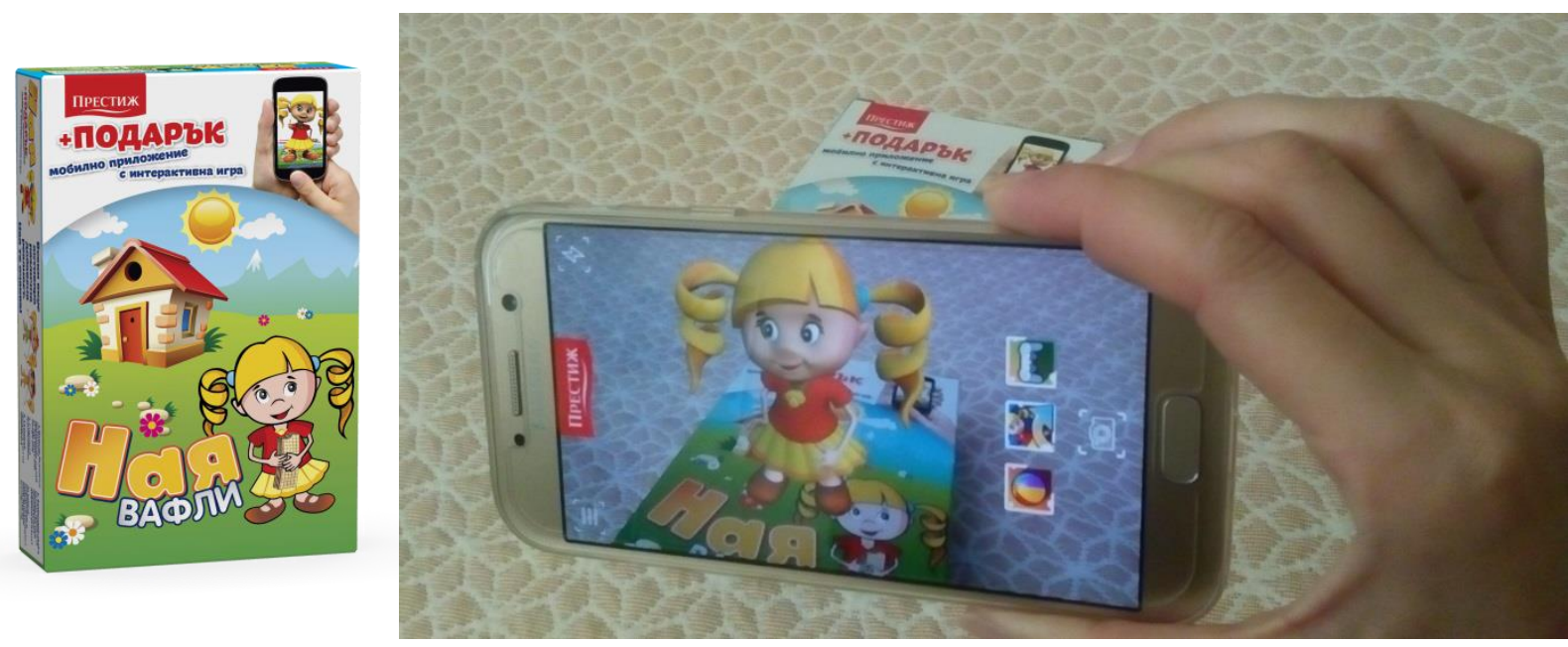

Figure 4. Packaging of wafers Naya (company Prestige 96) comes to life with ScanAR app.

Augmented Reality allows greater interactivity in the process of shopping. The result is much more entertainment and powerful interactions, creation of emotional relationships between customers and products. The product becomes personal when the user can put it in his personal world instead of the artificial environment of the stores. The personalization of the products and the ability to interact with them may urge customers to make real purchases. On the other hand, creating an emotional relationship between users and products stimulates customers to share their experiences with friends, colleagues, family and recently in social media. This tendency is a prerequisite for companies to build a community around their products that leads to high social visibility and presence on the market and in society.

Regarding to the criterion cost, creating a marketing or advertising campaign with Augmented Reality is cheaper than using traditional channels and media, such as print materials and TV channels.

\section{DISCUSSION}

Augmented Reality is used by many companies to improve their visibility on the market, increase sales, enhance customer experience, attract consumers' attention, create an unforgettable impression and give them new perceptions and feelings (10). It is very important the choice of technology to be in line with the company's goals. The use of innovative technologies, in particular Augmented Reality, should not be an end in itself. The use of some technology because it is modern and almost everyone is trying to use it, or because technology is attractive in itself is not a proper decision. The technology should be bound and implemented as part of company's activities.

Augmented Reality creates a new blended environment where computer-generated content improves perception and sense of the physical world.

Augmented Reality is a technology that can be used by a large audience since it is accessible through widespread hardware devices. Installing software is a quick and easy process and no special knowledge or preparations for use are required. At the same time, Augmented Reality technology offers opportunities for personalizing the experience and interaction with digital content. The virtual content can be put into the personal world of each user and can be emotionally related to him.

The deployment of Augmented Reality technology offers new ways of interactions between customers, products and services, and companies, complements and enriches users' 
KIRYAKOVA G., et. al.

world with new feelings and experiences (11). The technology has the potential to transform the business processes, especially those in trade - in both cases real and e-commerce. Augmented Reality is a tool that can be integrated into the overall activities of the companies to turn the attracted attention of consumers and their participation in organized campaign into real actions (orders, purchases, etc.). The mixing of the digital and physical world can create prerequisites for raising the processes of buying and selling at new levels and achieving the "ideal" shopping by improving and customizing the overall customer experience.

Augmented Reality allows companies to provide their customers added value (in the form of authentic experience), which creates and preserves the emotional connection between customers, products and company. The technology can be an effective tool in building loyalty to products or brands. Customers' loyalty is the factor that helps to increase companies' revenue, their recognition and presence on the marketplace and in the social life in the long term.

On the other side, implementing Augmented Reality in manufacturing can bring important competitive advantages for companies - faster design, production and delivery of the products on the market $(6,12)$. The technology can help reducing technical risks and errors, achieving a higher quality of the created products, shortening the development and manufacturing time.

Augmented Reality applications are also an appropriate tool for training and improving staff skills and qualification.

Augmented Reality technology reveals new levels and ways to collect data and provide feedback. Companies can analyze the collected data to gain insight into the "bigger" picture, identify trends and provide more personalized and engaging content to their users. The use of modern technologies, such as Augmented Reality, implies immediate feedback and measurability of organized campaigns.

\section{CONCLUSION}

The adoption of innovative technologies by companies is a natural process that is driven by business goals to meet the demands and requirements of their customers. The process of integration of new technologies into company's activities should be preceded by an assessment of the need of implementation in order to achieve the desired results.
The most important advantage of Augmented Reality is its role as a bridge that connects the digital and real worlds. Augmented Reality is a technology that is capable to enrich the real physical environment with computer-generated content and complement the reality with different sensory feelings. It transforms the way people interact with digital content information about surrounding world becomes interactive, accessible and digitally manipulative.

Augmented Reality has a great potential in many different areas such as advertising, marketing, education, engineering, entertainment, medicine and many others. Augmented Reality reveals new opportunities for business. It has become a powerful tool that allows companies to offer new rich experience and added value to their clients. Augmented Reality creates new business models, reveals different ways to expand and enrich access channels to consumers, attracts and engages their attention, integrates them into the world of companies, which leads to substantial profits for companies in the long-term aspect.

\section{REFERENCES}

1. Barck, J., How Augmented And Virtual Reality Are Transforming The Workplace, Recruiting Daily, 2017, http://recruitingdaily.com/virtual-realityworkplace-transformation/ (last access 26.06.2017)

2. Panetta, K., Gartner's Top 10 Strategic Technology Trends for 2017, 2016, http://www.gartner.com/smarterwithgartner /gartners-top-10-technology-trends-2017/ (last access 26.06.2017)

3. Azuma, R. T., A survey of augmented reality. Presence: Teleoperators and virtual environments, 6(4), 355-385, 1997.

4. The virtual and augmented reality market will reach $\$ 162$ billion by 2020 , Business Insider, 2016, http://www.businessinsider.com/virtualand-augmented-reality-markets-will-reach162-billion-by-2020-2016-8, (last access 26.06.2017)

5. Klamann, K., S. Krastev, Why Augmented Reality Will Be the Next Revolution in Retail, 2017, Strategy+Business, https://www.strategybusiness.com/article/Why-AugmentedReality-Will-Be-the-Next-Revolution-inRetail?gko=dbc10 (last access 26.06.2017)

6. Regenbrecht, H., Baratoff, G., \& Wilke, W., Augmented reality projects in the automotive and aerospace industries, IEEE Computer Graphics and Applications, 25(6), 48-56, 2005. 
7. Woollaston, V., End of the mechanic? BMW smart glasses make it possible for ANYONE to spot and fix a car engine fault just by looking at it, 2014, http://www.dailymail.co.uk/sciencetech/arti cle-2543395/The-end-mechanic-Smartglasses-make-possible-fix-car-engine-justlooking-it.html (last access 26.06.2017)

8. Augmented Reality + Tourism Industry: How it can Revolutionize your Tours \& Activities Business, Rezdy, 2016, https://www.rezdy.com/blog/augmentedreality-tourism-industry-can-revolutionizetours-activities-business/, (last access 26.06.2017)

9. Augmented Reality Applications in the Tourism Industry, Augment, 2016, http://www.augment.com/blog/augmentedreality-in-tourism/, (last access 26.06.2017)

10.Benefits of using Augmented Reality for business,

KIRYAKOVA G., et. al.

https://theappsolutions.com/blog/developm ent/ar-benefits-for-business/, (last access 26.06.2017)

11.Weinswig, D., Virtual And Augmented Reality Become Realistic Revenue Generators, Forbes, 2016, https://www.forbes.com/sites/deborahweins wig/2016/10/26/virtual-and-augmentedreality-become-realistic-revenuegenerators/\#7afe70ae6fc5, (last access 26.06.2017)

12.Virtual and Augmented Reality, Revolutionising complex product development and making the factory of the future a reality for today's manufacturers, http://www.advicemanufacturing.com/Virtual-andAugmented-Reality.html (last access 26.06.2017) 